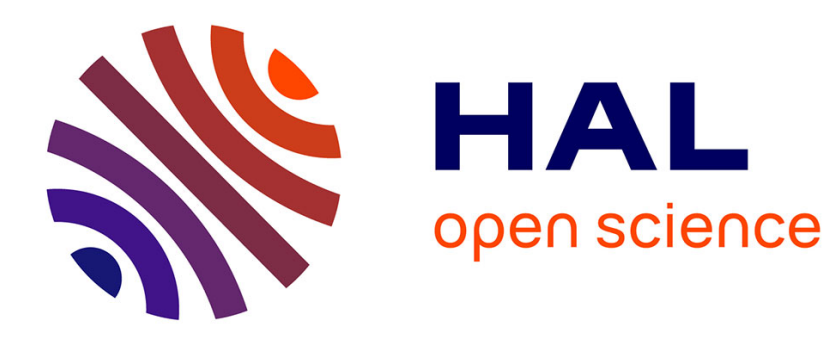

\title{
A Comparative Survey on Invisible Structured Light
}

David Fofi, Tadeusz Sliwa, Yvon Voisin

\section{To cite this version:}

David Fofi, Tadeusz Sliwa, Yvon Voisin. A Comparative Survey on Invisible Structured Light. Electronic Imaging 2004, Jan 2004, San José, CA, United States. 10.1117/12.525369 hal-01690535

\section{HAL Id: hal-01690535 \\ https://hal.science/hal-01690535}

Submitted on 23 Jan 2018

HAL is a multi-disciplinary open access archive for the deposit and dissemination of scientific research documents, whether they are published or not. The documents may come from teaching and research institutions in France or abroad, or from public or private research centers.
L'archive ouverte pluridisciplinaire HAL, est destinée au dépôt et à la diffusion de documents scientifiques de niveau recherche, publiés ou non, émanant des établissements d'enseignement et de recherche français ou étrangers, des laboratoires publics ou privés. 


\title{
A comparative survey on invisible structured light
}

\author{
David Fofi", Tadeusz Sliwa, Yvon Voisin \\ Le2i UMR CNRS 5158 - IUT Le Creusot, 12 rue de la Fonderie, 71200 Le Creusot, France
}

\begin{abstract}
This paper proposes a comparative survey on techniques of vision based on invisible structured lighting. We have classified them in three distinct families: InfraRed Structured Light (IRSL), Imperceptible Structured Light (ISL) and Filtered Structured Light (FSL). For each of them, definition, minimal configuration and main applications found in the literature are given. Then, we compare them regarding to several criteria: required equipment, light pattern coding, color analysis, texture analysis, motion analysis, security, use in non-controlled environment. The description of IRSL, ISL and FSL sensors will permit to sum up these techniques; the comparison will permit to evaluate performances and efficiency of each of them. We think that this study could be useful to researchers that are looking for a compromise between stereovision and structured light vision, combining the processing tools extent of the former with the point matching reliability and simplicity of processing of the latter.
\end{abstract}

\section{INTRODUCTION}

Structured light sensors, composed by one or more cameras and one or more light sources, are convincing alternative to passive stereoscopic sensors in controlled environment (industrial, medical), in weakly lighted environment (night vision, sub-marine vision) and in weakly textured environment (biometry, anthropometrics). However, they put up with a major disadvantage: the light pattern projection forms an invasive signal that can be objectionable in some cases. It yields to the loss or corruption of colorimetrical and textural information of the lighted surfaces, to the inconsistence of the optical flow and, moreover, to the offensive, indeed dangerous aspect of the illumination (think about potential danger of LASER sources, faces measurements even with slide light projector, etc.) In addition, some inspection systems, working in outdoor or partial outdoor environment, have to be discreet and without risks. Among these, systems of sensitive zone surveillance, systems of collision detection on some vehicles, systems of environment recognition used in robotics and many others can be mentioned. These systems have to acquire geometric measurements on objects that cross their detection field, without disrupting, modifying, or putting in danger the environment.

In order to benefit from the advantages of structured light vision while avoiding these drawbacks, we laid down the objective to design a sensor with light pattern projection in the non-visible spectrum. With this aim, several options occur, each one based on a different type of light: InfraRed Structured Light (IRSL), Imperceptible Structured Light (ISL) and Filtered Structured Light (FSL).

We propose a synthetic survey on IRSL, ISL and FSL: for each one, the working principle, further improvements and main applications are given. Efficiency and potentialities are compared according to several criteria.

The paper is divided as follow. After a brief introduction on structured light vision, a complete description of IRSL, ISL and FSL sensors is given in section 2: principle and geometry are explained, main publications are referred. In section 3, criteria for comparison of the sensors are listed and detailed. Section 4 summarizes our results on multi-criteria comparison. The paper ends, in section 5, with discussion and conclusion: advantages and drawbacks, suited applications, etc.

\footnotetext{
*d.fofi@iutlecreusot.u-bourgogne.fr; phone +33 (0)3 85731126 ; fax +33 (0)3 857310 97; www.le2i.com
} 


\section{SENSORS DESIGN}

A rapid description of each technique is given in this section. Beforehand, the basic principle of structured light vision is recalled.

\subsection{Structured Light Vision}

A structured light sensor is similar to a classical stereoscopic sensor with a camera replaced by a light source, as shown in Fig. 1: commonly, a laser or a slide projector. In its simplest form, structured light is a laser beam projecting a single dot onto the scene (Fig. 1, (i)). Since only one point is projected, correspondence is direct. However, scanning along both axes is required. A second solution consists in projecting a light plane (that appears as a single slit on the object surface Fig. 1, (ii)). Scanning along one axis is still necessary. This is the technique commonly used for 3D scanning. Shirai and Suwa proposed to apply it to the recognition of polyhedrons in 1971 [12]. In 1992, Strauss proposed a three-dimensional perception system based on this sensor [14]. Correspondence solving is quite simple: a single orthogonal translation of the light projector with respect to the slit ensures a single and unambiguous matching (intuitively, 3D points are obtained by intersecting a light plane with the line of sight).

In order to avoid a time consuming mechanical scanning, a last solution consists in projecting a multi-stripe patterns, a grid or multiple dots - that is a bi-dimensional pattern (Fig. 1, (iii) and (iv)). Will and Pennington are pioneers in that field of research [16] with their technique named grid coding. Let us mention the work of Hu, Jain and Sotckman [6] or Stockman and $\mathrm{Hu}$ [13]. For that kind of patterns, a correspondence problem occurs, that can be solved by coding the pattern, in a way that each token of light is easily distinguishable from the others. An exhaustive survey on coded structured light appeared in 1998 [1], and has been updated in 2004 [11].

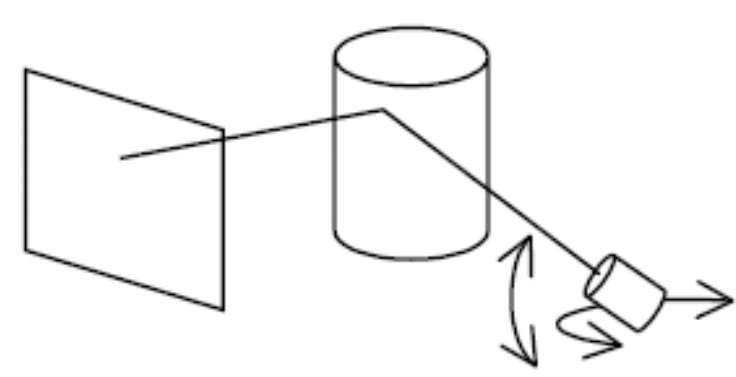

(i) Single dot

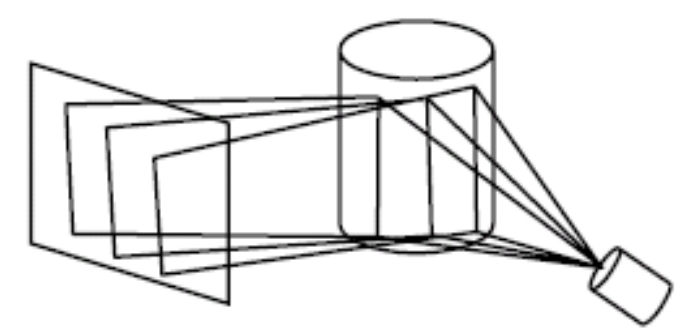

(iii) Stripe patterns

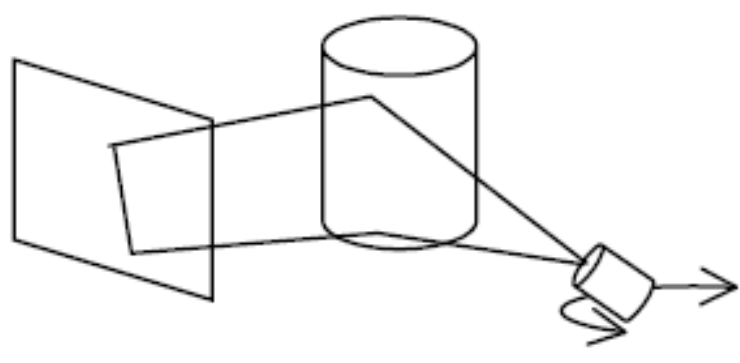

(ii) Single slit
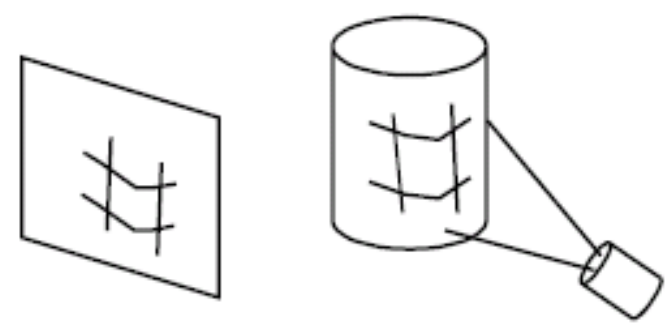

(iv) Grid, multiple dots

Fig. 1. Geometry of a structured light sensor 


\subsection{InfraRed Structured Light}

An infrared laser beam is used to generate invisible patterns that can be single dot, single line or bi-dimensional patterns as shown in Fig. 2. The light is usually projected in the near-infrared, i.e. from $640 \mathrm{~nm}$ to $2500 \mathrm{~nm}$ or from 4000 to 15 $600 \mathrm{~cm}^{-1}$. The scene is observed by a CCD camera, because of the spectral sensibility of CCD, from $300 \mathrm{~nm}$ to $1100 \mathrm{~nm}$ (an infrared camera is not necessary).

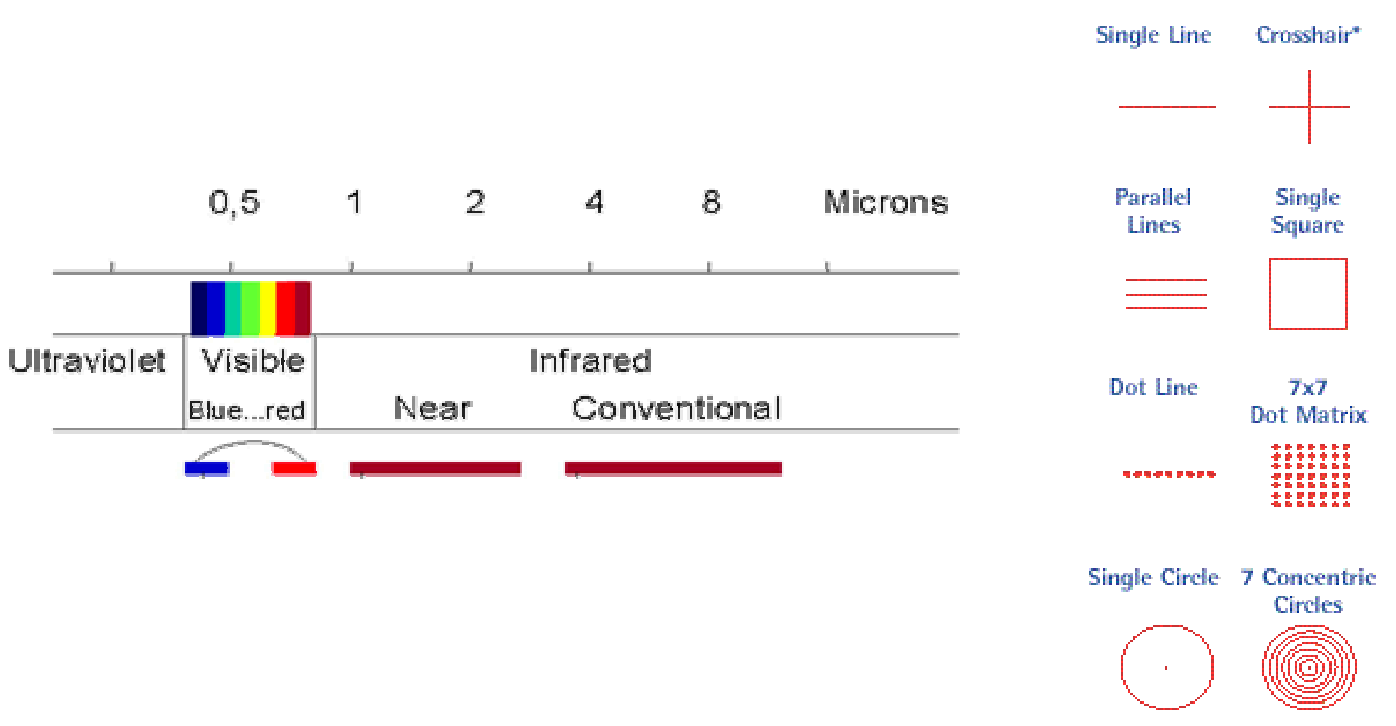

Fig. 2. Infrared structured light. (left) Typical wavelength. (right) Example of patterns.

This technique is widely used for 3D scanning, robot navigation and so on. Boverie, Devy and Lerasle recently used infrared structured light for 3D perception applied to airbag generation [3]. They also compared structured light and stereovision [2]: they concluded that stereoscopy gives very high reliability but remains heavy in terms of computational time, whereas structured light proposes a good compromise between accuracy and speed. They also recall one of the most interesting characteristic of structured light: its capability to retrieve 3D information from a non-textured surface.

Infrared structured light has also been used in omnidirectional vision [10]. A rotative sensor composed of two CCD cameras and a diffracted laser beam observed the scene along $360^{\circ}$. By filtering the images, this sensor is used for the $3 \mathrm{D}$ reconstruction thanks to structured light and color acquisition thanks to RGB information. A Cold filter is used to grab infrared structured light image.

\subsection{Imperceptible Structured Light}

Imperceptible structured light sensors are composed by a unique light source and two cameras (Fig. 1). The light source projects a light pattern followed by its complement (inverse pattern) onto the scene at high frequency, so that the resulting pattern is uniform. The first camera is synchronized with the projection of the first pattern and permits to reconstruct the scene thanks to the capabilities of structured light vision; the second camera has a longer integration time and observes the scene under uniform light (as a result of pattern and complement projection) which permits to get a classical gray-level or colored image and processes it. This technique is known as imperceptible structured light [7][9]. The aim is to combine the advantages of structured lighting (easy correspondence and reconstruction of homogeneous surfaces) with the advantages of classical vision (color or texture analysis, etc.) in order to achieve a 3D reconstruction of the scene with the mapping of surface colors and textures. 
Whether the frequency of projection reaches the critical flicker frequency (from $75 \mathrm{~Hz}$ according to Watson [15]), the pattern and the inverse pattern are visually integrated over time, so that the result is the appearance of flat field ("white" light) - Fig. 4. Critical flicker frequency is defined as the highest frequency at which a person can detect the flicker in a flickering light source.

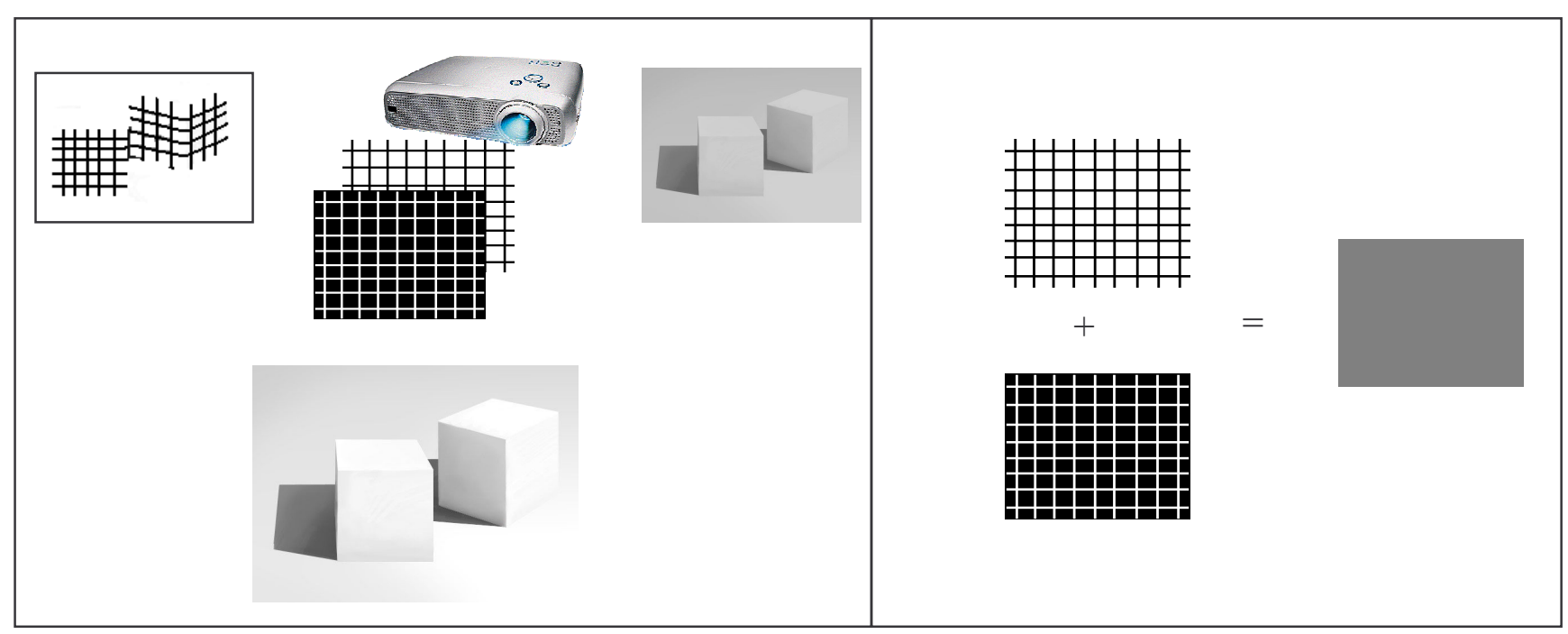

Fig. 3. Principle of the ISL sensor

Fig. 4. Resulting and projected patterns

\subsection{Filtered Structured Light}

The light source is filtered so that only infrared structured light passes. The light pattern can be projected through a laser source or a video-projector. An IR filter, set in front of the light source, permits to "cancel" light below $750 \mathrm{~nm}, 800 \mathrm{~nm}$, $850 \mathrm{~nm}$, etc. by acting as an high-pass filter. Although, filtered structured light seems very similar to infrared structured light, we will try, in section 3 , to evaluate the differences between both.

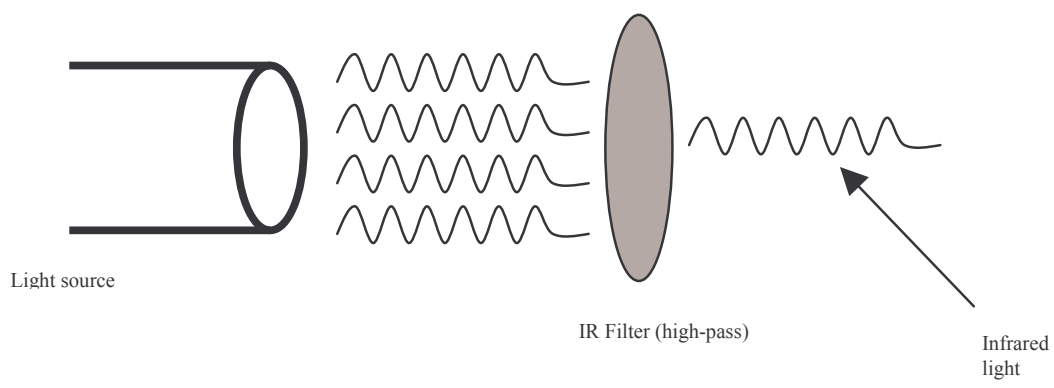

Fig. 5. Principle of filtered structured light 


\section{A MULTI-CRITERIA COMPARISON}

This section aims to compare the three techniques regarding several criteria as required equipment, pattern codification, color, texture, edges and motion analysis, suitability and security, etc.

\subsection{Required Equipment}

Table 1 lists the required equipment for each sensor. It is clear that ISL sensor requires a major occupancy due to the need of a video-projector (larger than a laser source) and two CCD cameras. It is also the most expensive of the three sensors. However, video-projector offers some advantages: the possibility to encode the pattern, to use the sensor in a "one-shot" acquisition process (without scanning), to change and design dynamically the pattern, to project a sequence of patterns, etc. Table 2 summarizes the comparison between both light sources.

\begin{tabular}{|c|c|c|c|}
\cline { 2 - 4 } \multicolumn{1}{c|}{} & Light Source & Camera & $\begin{array}{c}\text { Additional } \\
\text { Requirement }\end{array}$ \\
\hline IRSL & $\begin{array}{c}\text { Only one light source is } \\
\text { needed: laser beam, } \\
\text { diffracted laser beam. }\end{array}$ & $\begin{array}{c}\text { One CCD camera or, } \\
\text { eventually, one infrared } \\
\text { camera. }\end{array}$ & None \\
\hline ISL & $\begin{array}{c}\text { One video-projector is } \\
\text { needed. }\end{array}$ & $\begin{array}{c}\text { Two CCD cameras are } \\
\text { needed. }\end{array}$ & None \\
\hline FSL & $\begin{array}{c}\text { One light source is needed: } \\
\text { laser beam, diffracted laser } \\
\text { beam or video-projector. }\end{array}$ & $\begin{array}{c}\text { One CCD camera or, } \\
\text { eventually, one infrared } \\
\text { camera. }\end{array}$ & One IR \\
\hline
\end{tabular}

Table 1. Equipment

\begin{tabular}{|l|l|}
\hline \multicolumn{1}{|c|}{ Laser Light Source } & \multicolumn{1}{c|}{ Video-projector } \\
\hline - $\begin{array}{ll}\text { Mechanical scanning is required for single dot or slit } \\
\text { Bi-dimensional pattern cannot be coded }\end{array}$ & "One-shot" acquisition \\
& $-\begin{array}{l}\text { Coded pattern } \\
\text { - }\end{array}$ \\
& \\
\hline
\end{tabular}

Table 2. Comparison of laser and video-projector

\subsection{Pattern Codification}

Let us now compare the sensors in terms of pattern codification. It is well known that coded structured light permits to increase the potentialities of structured light vision [1][11]. There are three main strategies in order to encode patterns: time-multiplexing by projecting a sequence of different patterns onto the objects, spatial codification when the coding of each pattern pixel depends on its neighborhood, and direct codification when each pattern pixel carry its own code. Moreover, coding can be based on binary primitives (black or white), gray-level primitives or color primitives. Table 3 summarizes the possible codification strategies for each sensor. It is shown that ISL sensor guarantees a wide and complete codification. On the contrary, IRSL sensor cannot be coded at all (laser source prohibits easy codification).

Due to the possible use of video-projector for FSL sensor, it is possible to encode the patterns through spatial binary codification or time-multiplexing codification. It is one of the main difference between IRSL and FSL: the latter offers modularity but with the disadvantage of harder implementation.

In addition, it has to be mentioned that ISL sensor and FSL sensor could be coded in an hybrid way. For example, by mixing visible code with invisible code, that is to say, by adding an invisible component to the classical codification primitives. 


\begin{tabular}{|c|l|l|}
\hline IRSL & \multicolumn{1}{|c|}{ ISL } & \multicolumn{1}{c|}{ FSL } \\
\hline - The pattern cannot be coded & $\begin{array}{l}\text { The pattern can be color-coded, } \\
\text { gray-level-coded or binary-coded. } \\
\text { The codification can be time- } \\
\text { multiplexed (temporal codification). } \\
\text { An hybrid (visible+invisible) } \\
\text { codification can be imagined. }\end{array}$ & $\begin{array}{l}\text { The pattern can be binary-coded. } \\
\text { - The codification can be time- } \\
\text { multiplexed (temporal codification). } \\
\text { An hybrid (visible+invisible) } \\
\text { codification can be imagined. } \\
\text { A multi-filter sensor can be } \\
\text { aligned. }\end{array}$ \\
\hline
\end{tabular}

Table 3. Pattern codification potentialities

\subsection{Color, Texture, Edges and Motion}

Is it possible to recover information as color, texture, edges and motion from a structured light sensor? In other words, can structured light vision give as much information as stereovision? It is known that the projection of a bi-dimensional pattern onto the scene disallows usually to grab color, texture or edges information. However, by using imperceptible structured light, the second image provides this information as the second camera grabs the scene in more or less the same conditions than a monocular sensor does. Moreover, motion algorithm based on optical flow or 3D tracking, can easily be adapted to ISL sensor.

On the other hand, IRSL or FSL sensor does not directly permit such possibility unless an additional image is acquired without illumination. 3D scanners perform that way for texture mapping. Besides, motion analysis seems very difficult to achieve with IRSL and FSL sensor. At the very least, they are not adapted to such operation (see Table 4).

\begin{tabular}{|c|c|c|c|c|}
\hline & Color & Texture & Edges & Motion \\
\hline IRSL & $\begin{array}{l}\text { By acquiring an } \\
\text { additional color image }\end{array}$ & $\begin{array}{l}\text { By acquiring an } \\
\text { additional image }\end{array}$ & $\begin{array}{l}\text { By acquiring an } \\
\text { additional image }\end{array}$ & Seems difficult \\
\hline ISL & $\begin{array}{l}\text { By using the second } \\
\text { camera image }\end{array}$ & $\begin{array}{l}\text { By using the second } \\
\text { camera image }\end{array}$ & $\begin{array}{l}\text { By using the second } \\
\text { camera image }\end{array}$ & $\begin{array}{l}\text { By using the second } \\
\text { camera image }\end{array}$ \\
\hline FSL & $\begin{array}{l}\text { By acquiring an } \\
\text { additional color image }\end{array}$ & $\begin{array}{l}\text { By acquiring an } \\
\text { additional image }\end{array}$ & $\begin{array}{l}\text { By acquiring an } \\
\text { additional image }\end{array}$ & Seems difficult \\
\hline
\end{tabular}

Table 4. Color, texture, edges and motion analysis

\subsection{Outdoor and Security}

Finally, let us discuss about outdoor applications and security. For the sensors based on laser light source, a compromise has to be made between laser power and security. However, structured light vision based on structured light has already been used in outdoor environment, either for mobile robotics [8] (obstacle detection) or underwater robotics [4][5]. Especially, IRSL sensor is the most suited to outdoor operations thanks to the reduced occupancy, the easy implementation and the laser robustness to ambient light.

ISL is a secure sensor but is not very well adapted to outdoor measurement. It requires two cameras and a video-projector (i.e. a big occupancy, a precise calibration process, etc.). Moreover, video-projectors are still very sensitive to ambient light which makes difficult their use in a non-controlled environment.

\section{SUMMARY}

Let us now summarize the comparison we made between IRSL, ISL and FSL sensors. Table 5 shows synthetic results on this comparison. Symbol $\sim$ means an indetermination or something like "perhaps, but difficult". Table 6 gathers the major advantages and drawbacks of the three sensors. 


\begin{tabular}{|c|c|c|c|}
\hline \multicolumn{1}{|c|}{ SENSOR } & IRSL & ISL & FSL \\
\hline CRITERION & Yes & No & Yes \\
\hline Laser beam & $\sim$ & Yes & Yes \\
\hline Video-projector & No & Yes & No \\
\hline Colour codification & $\sim$ & Yes & Yes \\
\hline Binary codification & No & Yes & Yes \\
\hline Hybrid codification visible/invisible & $\sim$ & Yes & Yes \\
\hline Sequence of patterns & Yes & No & No \\
\hline Mechanical scanning required & Yes & Yes & Yes \\
\hline Colour analysis & Yes & Yes & Yes \\
\hline Texture analysis & Yes & Yes & Yes \\
\hline Texture mapping & Yes & Yes & Yes \\
\hline Edge detection & $\sim$ & Yes & $\sim$ \\
\hline Motion analysis & Yes & $\sim$ & Yes \\
\hline Outdoor & & $\sim$ \\
\hline
\end{tabular}

Table 5. Comparison of IRSL, ISL and FSL

\begin{tabular}{|c|c|c|}
\hline SENSOR & है & 乌ิ \\
\hline IRSL & $\begin{array}{l}\text { - Highest resolution } \\
\text { - High accuracy } \\
\text { - Easy implementation }\end{array}$ & $\begin{array}{l}\text { - Mechanical scanning } \\
\text { - No codification }\end{array}$ \\
\hline ISL & $\begin{array}{l}\text { - Codification capabilities } \\
\text { - Modularity and adaptivity } \\
\text { - Colour image + SL image } \\
\text { - One-shot reconstruction }\end{array}$ & $\begin{array}{l}\text { - Occupancy } \\
\text { - Synchronization between projection } \\
\text { and capture }\end{array}$ \\
\hline FSL & $\begin{array}{l}\text { - High resolution } \\
\text { - Coded pattern can be designed } \\
\text { - Multi-band pass sensor }\end{array}$ & $\begin{array}{l}\text { - A filter is required } \\
\text { - Not as good as IRSL when } \\
\text { composed by laser source, not as good } \\
\text { as ISL when composed by video- } \\
\text { projector }\end{array}$ \\
\hline
\end{tabular}

Table 6. Advantages and drawbacks of IRSL, ISL and FSL 


\section{CONCLUSIONS}

Three structured light techniques have been presented in this paper: InfraRed Structured Light, Imperceptible Structured Light and Filtered Structured Light. They permit to benefit from the advantages of structured light vision as easy segmentation and matching, reliable and precise 3D reconstruction, without the drawback of projecting an invasive signal onto the scene.

Our conclusions is that IRSL offers high precision and resolution, ISL is modular and adaptable (one sensor can be used for many applications by changing the pattern) and FSL offers a good compromise between both, but is not as good as IRSL when composed by a laser source and not as good as ISL when composed by a video-projector. IRSL is mainly adapted to 3D scanning, profilometry and obstacle detection for robotics and ISL permits "one-shot" reconstruction, surface and shape defects detection.

We think that this study could be useful to researchers that are looking for a compromise between stereovision and structured light vision, combining the processing tools extent (color analysis, texture analysis, motion analysis) of the former with the point matching reliability and simplicity of processing of the latter. A complete application could be the $3 \mathrm{D}$ reconstruction of the environment with texture and color mapping - a machine vision that allows dimensional, colorimetrical and textural measurements, capable to simultaneously control shape and aspect defects. Furthermore, the description of IRSL, ISL and FSL sensors permitted to sum up these techniques, poorly known and under-used at times; the comparison permitted to evaluate performances and efficiency of each of them.

\section{REFERENCES}

1. J. Batlle, E. Mouaddib, J. Salvi, "Recent Progress in Coded Structured Light as a Technique to Solve the Correspondence Problem”, Pattern Recognition, 31(7), pp. 963-982, 1998.

2. S. Boverie, M. Devy, F. Lerasle, "Comparison of Structured Light and Stereovision Sensors for New Airbag Generations”, Control Engineering Practice, 11, pp. 1413-1421, 2003.

3. S. Boverie, M. Devy, F. Lerasle, “3D Perception for New Airbag Generations", 15 $5^{\text {th }}$ IFAC World Congress on Automatic Control, Barcelona, Spain, 2002.

4. M. J. Chantier, J .Clark, M. Umasuthan, "Calibration and Operation of an Underwater Laser Triangulation Sensor: the Varying Baseline Problem”, Optical Engineering, 36(9), pp. 2604-2611, 1997.

5. J. Forest, J. Salvi, J. Batlle, "Image Ranging System for Underwater Applications", IFAC Conference on Maneuvering and Control of Marine Craft, Aalborg, Denmark, 2000.

6. G. Hu, A.K. Jain, G. Stockman, "Shape from Light Stripe Texture", Proceedings of the International Conference on Computer Vision and Pattern Recognition, pp. 412-414, 1986.

7. M. Livingston, "Vision-Based Tracking with Dynamic Structured Light for Video See-through Augmented Reality", PhD Thesis, University of North-Carolina, 1998.

8. L. Matthies, T. Balch, B. Wilcox, "Fast Optical Hazard Detection for Planetary Rovers using Multiple Spot Laser Triangulation", IEEE Proceedings of the International Conference on Robotics and Automation, Albuquerque, USA, 1997.

9. R. Raskar, G. Welch, M. Cutts, A. Lake, L. Stesin, H. Fuchs, "The Office of the Future: A Unified Approach to Image-Based Modeling and Spatially Immersive Displays”, Proceedings of SIGGRAPH, Orlando, Florida, 1998. 
10. O. Romain, T. Ea, C. Gastaud, P. Garda, "Un Capteur Multi-Spectral de Vision Panoramique 3D”, Actes des journées francophones des jeunes chercheurs en analyse d'images et perception visuelle (ORASIS'2001), Cahors, France, Juin 2001.

11. J. Salvi, J. Pagès, J. Batlle, "Pattern Codification Strategies in Structured Light Systems", To appear in Pattern Recognition, 2004.

12. Y. Shirai, M. Suwa, "Recognition of Polyhedrons with a Range Finder", Proceedings of the International Joint Conference on Artificial Intelligence, pp. 80-87, 1971.

13. G. Stockman, G. Hu, "Sensing 3-D Surface Patches using a Projected Grid", Computer Vision and Pattern Recognition, pp. 602-607, 1986.

14. O. Strauss, "Perception de l'Environnement par Vision en Lumière Structurée : Segmentation des Images par Poursuite d'Indices", PhD Thesis, University of Montpellier II, January 1992.

15. A. B. Watson, "Temporal Sensitivity", Handbook of Perception and Human Performance, K. Boff, L. Kaufman and J. Thomas editors, New-York, 1986.

16. P.M. Will, K.S. Pennington, "Grid Coding: A Preprocessing Technique for Robot and Machine Vision", Proceedings of the International Joint Conference on Artificial Intelligence, pp. 66-70, 1971. 